\title{
Natural and man-made flooding hazards at the torrents in the town of Thessaloniki
}

\author{
S. Stefanidis, F. Tziaftani \& C. Chatzicristaki \\ Institute of Mountainous Water Management and Control, \\ Aristotle University of Thessaloniki, Greece
}

\begin{abstract}
Streams and rivers, whether large or small, cross the majority of our country's urban centers. These streams should be an inseparable part of urban planning in modern cities. The town of Thessaloniki is subjected to torrents that stem from the surrounding hills and, after crossing the urban areas of Thessaloniki, outfall in the Thermaikos gulf.

These torrents belong in the category of streams of hilly areas, so the environmental potential is mild. Intense floods appearing in Thessaloniki's conurbation happen mostly due to human activity.

The purpose of this paper is the research of the natural factors that form the torrential potential of the research area (climate, relief, vegetation, geological support) and the man-made activities at the stream beds.

The present study shows that moderate-sized precipitation received by the region in conjunction with mild relief would prevent the appearance of intense flooding in the region. However, the small percentage of forest vegetation at the watersheds and the fragile geological support increase flooding. Apart from natural factors of the torrentiality, an important role in the statement of flood phenomena is man-made interventions inside the stream beds.
\end{abstract}

Keywords: torrential environment, man-made activities, flooding hazard, stream bed.

\section{Introduction}

The method and the process of movement of runoff water in the watershed depend on natural and anthropogenic factors. Regarding the natural factors, these 
are the climate, the relief, the vegetation and the geological support, while anthropogenic factors (both in the watersheds and in the beds of streams) are the forest fires, clearances, trespasses dormitory, fragmentary implementation of work, inadequate technical work and rejects of waste-rubble in the streams beds. Certainly the dominant element in the incidence of flooding is the amount of rainfall, but in most cases, the flooding would be alleviated if we had no human intervention.

The purpose of this study is to investigate natural and anthropogenic factors of torrentiality and their effect on increasing flood risk in the area.

\section{Research area}

The town of Thessaloniki is crossed by streams that flow from the surrounding hills, and after crossing urban areas this results in an outfall into the Thermaikos gulf.

The area is grooved by 7 torrential streams as follows: torrent Dendropotamos, which had 7 sub-basins (Oreokastrou, Melissoxoriou, Litis, Efkarpia, Filirou, Asvestoxoriou and Polichnis) torrent of Konstantinidi, torrent of Ano Toubas, torrent of Kipou tou Kalou, torrent Agios Panteleimon and torrent of Eleona. The total area of the watersheds of the research area is $\mathrm{F}=123.66 \mathrm{Km}^{2}$.

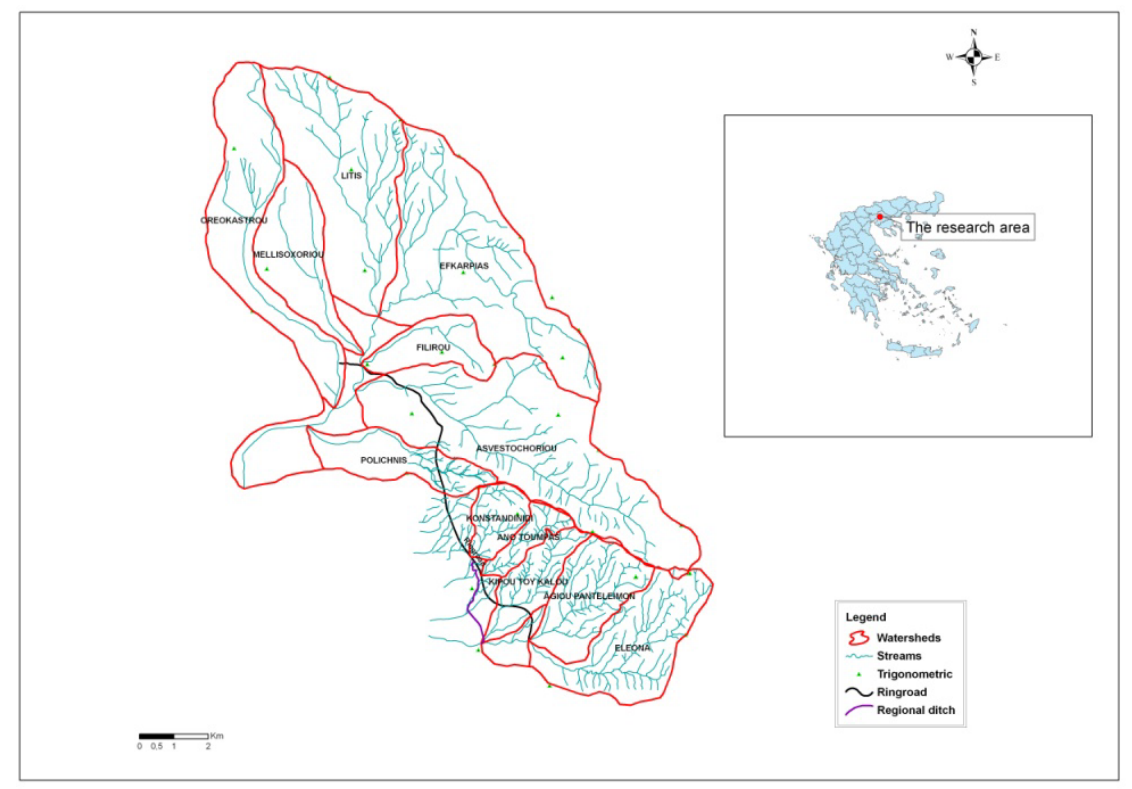

Figure 1: $\quad$ The research area. 


\section{Research method}

For the accomplishment of the goals of this research, the following methods were applied. The research area was mapped. The watersheds were defined and the whole area was digitized by the topographical maps of the Military Service (scale 1:50000). The digitization of the hydrographic network, the watershed areas' boundaries and the contour lines was realized by using Geographical Information Systems. This was followed by the specification of the morphometrics and hydrographic features using the ArcGIS 9 program. After that the four basic torrent factors were analyzed and the torrent potential of each torrent was defined. The following steps were followed in order to complete the above-mentioned research.

- The meteorological data of the meteorological station of the Aristotle University were collected, evaluated and processed

- A vegetation (plant cover) map was conducted (scale 1:50000) using thematic maps of Greece

- The bedrock of the research area was derived from the detailed map of the Institute of Geology and Mineral Exploration of Greece (IGME). The next procedure was the bedrock's classification on torrential petrographic formation.

On completion of the above-mentioned work and after the determination of the torrent environment, we visit the area several times so as to see the manmade activities in the main streams of the torrents.

\section{Results}

\subsection{Morphometrical and hydrographical results}

According to Kotoulas [1], the most important features of the basin expressing morphometrics are: the surface area, the perimeter, the shape of the basin, the degree of roundness, minimum, maximum and medium altitude, the basin mean slope, the maximum torrential altitude and the maximum relief.

From the hydrographical aspect $\tau \alpha$ the most important features of the basin are: shape and density of the hydrographic network, the length and main slope of the stream. The morphometric and hydrographic characteristics of the torrential streams of the research area estimated using GIS techniques (Myronidis [2]).

We found that the research area consisted of 7 basins. The total surface of the area is $\mathrm{F}=123.66 \mathrm{Km}^{2}$. Of all the torrents the largest surface is in the basin of Dendropotamos which is $\mathrm{F}=97.37 \mathrm{Km}^{2}$ and the smallest is in the basin of Ano Toumpas, with surface $\mathrm{F}=2.13 \mathrm{Km}^{2}$. In addition, we found that the minimum altitude of the region is Hmin $=20 \mathrm{~m}$ and the maximum is $\mathrm{Hmax}=700 \mathrm{~m}$. As for the main slopes of the torrents, they are between $9 \%$ and $29.1 \%$. Finally, one of the morphometric characteristics worth mentioning is the density of the hydrographical network $\mathrm{D}$, which takes values $1.20-5.15 \mathrm{Km} / \mathrm{Km}^{2}$. The main 
stream length ranges from 3.53 to $11.68 \mathrm{Km}$ and the main slope of the main stream $\mathrm{Jk}$ takes values from $1 \%$ to $8 \%$.

\subsection{Basic factors of torrentiality}

The basic factors of torrentiality, which specify the torrent environment of a region, are the climate, relief, vegetation and geological support (Stefanidis [3]).

\subsubsection{Climate}

The climate is the attack factor on the geological support, both for the production and transport of sediments. For the years between 1946 and 2002 the total annual amount of precipitation has an average value of $453 \mathrm{~mm}$ with a maximum of $54.2 \mathrm{~mm}$ in November and a second maximum in May of $46.5 \mathrm{~mm}$. During the growing season (March-September) the rainfall amounts to $230.4 \mathrm{~mm}$ and during the afforestation period (October-February) the rainfall amounts to $222.8 \mathrm{~mm}$. The annual amount of precipitation in the growing season has the form of heavy rains and storms (Stefanidis and Stathis [4]). The driest months of the year are July (26.9 mm) and August (19.8 mm).

It is important that, in addition to the abnormal distribution of rainfall, intense maximum daily rainfall depth aggravates the torrential phenomena (maximum daily rainfall depth: $98 \mathrm{~mm} / 24 \mathrm{~h}$ ).

\subsubsection{Relief}

The role of the relief is regulating, while it determines the intensity with which the climate acts and can moderate or intensify the flood phenomena. In terms of relief, the altitude and current gradients in the region are particular important. The small altitude that dominates in the region results in the larger extent occupying the torrents of the hilly regions with a percentage of $73.28 \%$, followed by the torrents of the lowland regions with a percentage $26.44 \%$ and finally a very small area of $0.27 \%$ occupied by the torrents in semi-mountainous areas.

\subsubsection{Vegetation - plant cover}

Vegetation (plant cover) and, in particular, forest cover, is the torrent basic factor that prevents torrent action and we have to notice that is the only one of the basic factors that man can change.

The research area belongs to the vegetation zone, which is called Quercetalia Pubescentis. On July 6, 1997 a big fire occurred in the urban forest of Thessaloniki that burnt out $63 \%$ of the forest vegetation. This has, as a consequence, increased the flooding hazard in the region.

The current land use in the area is forests $12.57 \%$, agricultural areas $32.37 \%$ settlements $26.28 \%$ and grazing lands $28.78 \%$. According to the analysis of land use, we can say that the vegetation cannot act in a protective role.

\subsubsection{Geological support}

According to our research, Thessaloniki consists mostly of sedimentary rocks $(\mathrm{S})$ with a percentage of $42.5 \%$. Also important are the presence of the schist formation $(G)$ with a percentage of $10.86 \%$, the flysch formation $(F)$ with a 
percentage of $16.78 \%$ and the magmatic formation (M) with a percentage of $16.55 \%$. Generally, the torrential petrographic formations of the Thessaloniki's town are vulnerable to erosion according to Aulitzky [5].

\subsection{Man-made factors of torrentiality}

In the region of Thessaloniki's town, the increasing housing needs and the landuse changes have created intense problems due to the changes that befell in the torrential environment of the region of Stefanidis [6].

Modern Thessaloniki was developed without land-planning. This anarchist urban sprawl, which derived from successive sections of urbanization due to exceptional events, led to abuse of the region that focused on public places, particularly the beds of streams (Pavlides and Fillipides [7]). Figures 2 and 3 feature some typical man-made problems that interfere with the torrential streams of Thessaloniki town.

All these interferences within directly alter stream bed geometry and increase the water and sediment discharges. Moreover, deforestations from fires and clearances damage the protective mantle of forest vegetation.

Here is a typical man-made interference in the torrential streams of Thessaloniki town.

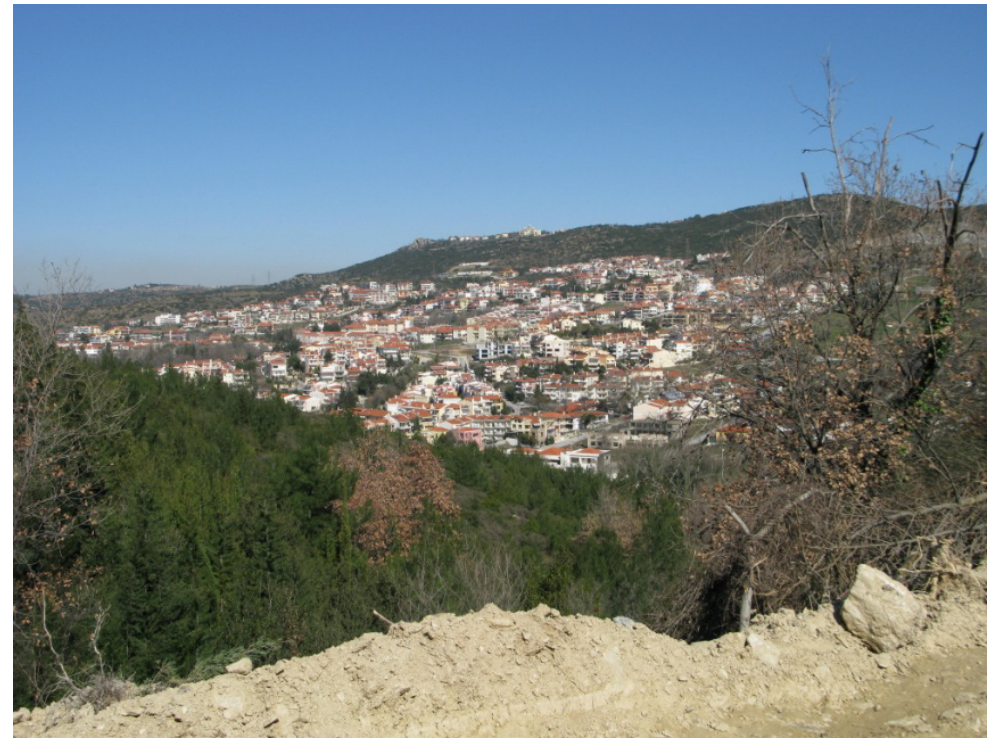

Figure 2: Residential development in the watershed of Asvestoxoriou.

\section{Conclusions and discussion}

After the mapping of the area, it was found out that the research region was grooved by 7 independent torrents. 


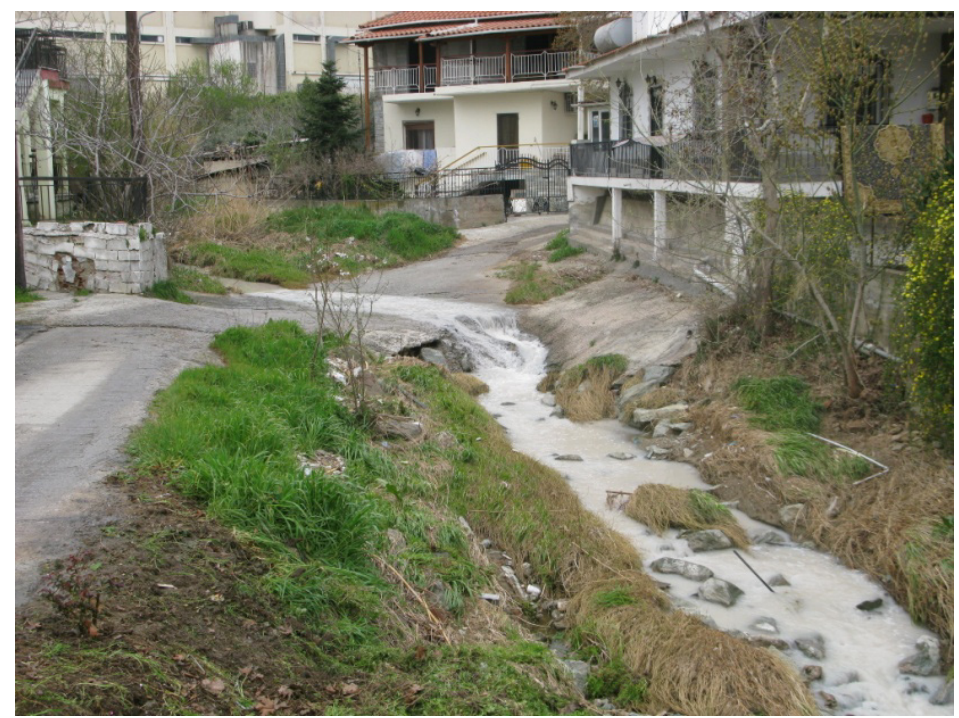

Figure 3: Narrowing the bed of the stream.

For the determination of the torrent environment, we analyzed the basic factors of torrentiality in the research area (climate, relief, vegetation, geological support). It showed that moderate-sized precipitation received by the region in conjunction with mild relief would prevent the appearance of intense flooding in the region. However, the small percentages of forest cover of the river, backed by the fragile geological formations, increase the flooding.

Apart from natural factors of torrentiality, an important reason for floods occurring is the man-made interventions within the streams. After our visits in the area we found that many of the streams of Thessaloniki town have been made more susceptible to flooding by the narrowings of the beds, inadequate structures and the impermeability of the surface of the watersheds, which has as a consequence dramatically increased the factor of runoff in the area.

In the area of Thessaloniki town the torrential environment is not intensive, although the increasing residential development has led to abuse of the central beds of streams. In many cases, flood phenomena would be alleviated if there were no intense anthropogenic interferences.

Finally, because of the effort of configuration, a new flood-preventing bed is considered unfeasible as the only solution to reduce the floods is the application of a combined forest techniques correction system with flood control works, which will always be necessary in the mountainous watersheds.

We can say that the torrents which have the fire anti erosion and flood control works constructed offer a reliable protection whereas the biggest risk is at the Dendropotamos basin where we have to implement a protection project. The effort of configuring a new flood-preventing bed is considered unfeasible as the only solution to reduce the floods is the application of a combined forest 
techniques correction system with flood control works which will always be founded in the mountainous watersheds.

\section{References}

[1] Kotoulas D., Torrents in Northern Greece, Readership Thesis, GE.MEL.ER Publication, 1970

[2] Myronidis D., Rational management of mountainous watersheds by developing geographical information system $\mathrm{PhD}$ Thesis, Publication, 2006

[3] Stefanidis P., The torrents of the Thessaloniki area. Scientific Annals of the department of Forestry and Natural Environment. Vol. LE/1, p. 511-528, 1992

[4] Stefanidis P., Stathis D., The streambeds as an element of the urban tissue of the Thessaloniki conurbation. International Symposium under the auspices of the School of Architecture, A.U.Th. Reconstruction of declining and destroyed areas of Europe, Thessaloniki, p. 146-155, 2001

[5] Aulitzky H., Preliminary two - fold classification of torrents. Mittelunge der forstlichen bunderversuchanstalt, Wien p. 144, 1982

[6] Stefanidis P., The torrent problems in Mediterranean Areas (example from Greece). Proc. IUFRO XX Congress. Finland, 1995

[7] Pavlides Th., Fillipides E., Administrative land planning of the urban sites on the banks of the Dendropotamos stream in Western Thessaloniki. International Symposium under the auspices of the School of Architecture, A.U.Th. Reconstruction of declining and destroyed areas of Europe, Thessaloniki, p. 157-174, 2001 